DOI: 10.14526/2070-4798-2020-15-1-89-95

\title{
Self-assessment of the University physical and non-physical education profile students physical development
}

\author{
Larisa K. Buduk-ool*, Ayana M. Khovalyg \\ Tuva state University \\ Kyzyl, Russia \\ ORCID: oooo-ooo3-3712-o703, buduk-ool@mail.ru \\ ORCID: oooo-ooo3-0496-7334,choixam@mail.ru
}

\begin{abstract}
Physical culture of students is an important component of students ' life activity during their studies at the University. It contributes to the student's adaptation not only to educational, but also to socio-psychological activities. In the system of physical education in higher education institutions, the proportion of people with motivation for a healthy lifestyle does not increase. There is a decrease in the motor activity of students. Under the influence of high mental and psychoemotional load, external information stress constantly increases social and psychological pressure, more often there is a strain on the compensatory and adaptive systems of the body. It leads to a violation of the daily routine, nutrition, increased risk of diseases and ultimately to a decrease in the effectiveness of the educational process and limiting professional employment prospects. Materials and research methods. The article is devoted to a comparative analysis of the Tuvan University physical and non-physical education faculty students lifestyle characteristics. To study the lifestyle of Tuvan students, a questionnaire was used. It included students' self-assessment of material and living conditions, health, physical development, nutrition, and socio-demographic characteristics of respondents. Results. Most girls and boys rate their physical development as good. Only about $15 \%$ of students regularly do morning exercises, and these are mainly students from the group of non-physical zones, young people from the field of physical education believe that they are already quite busy in the chosen sports and they do not need to do morning exercises. More and more respondents in non-physical fields receive good nutrition. Constantly malnourished more among young people in the physical field. Most respondents do not smoke, but non-physical education students have more people with irregular smoking. A rather high percentage of respondents who drink alcohol on holidays, especially in the non-physical group, in the other group they are three times less. Lack of personal interest in improving physical condition and maintaining health is especially characteristic of non-physical students. Non-physical boys and girls justify their interest in improving health with a high-response traditional response. Among respondents in the physical field, students indicate fatigue due to excessive physical activity.
\end{abstract}

Keywords: physical development, students, self-assessment of health, bad habits.

For citation: Larisa K. Buduk-ool*, Ayana M. Khovalyg. Self-assessment of physical development of students of physical and non-physical education profile of the University. Russian Journal of Physical Education and Sport. 2020; 15(1): 74-79. DOI: 10.14526/2070-4798-2020-15-1-89-95

\section{INTRODUCTION}

The physical culture of students is an important component of the students life during their studies at the university. Physical activity and sports contribute to the student's adaptation not only to educational, but also to socio-psychological activities. In the system of physical education in universities with an obvious increase in hours of physical education and sports, the proportion of people motivated by a healthy lifestyle does not increase. This is due not only to changes in the economy, ecology, but also to the lifestyle of young people who are becoming more and more inactive due to the widespread introduction of modern gadgets and a decrease in motor activity. Under the influence of high mental and psychoemotional stress, external informational tension, social and psychological stresses constantly increase. The tension of the compensatory-adaptive systems of the body occurs. It leads to disruption of the diet, nutrition, increased risk of diseases and, ultimately, a decrease in the effectiveness of the educational process and limiting the prospects for professional employment. 
Students represent a special social group. It is characterized by a higher educational qualification, intellectual level and social activity than other peers. Youth sports and athletic activity is an indicator of personality formation, reflecting their needs, motives and interests $[1,2]$.

From the point of view of the student period influence on a health problem, it should be emphasized that this stage of young people's life is characterized by specific working and living conditions, the need to adapt to a number of new factors. Even the first years of study at the university lead to adaptation of the stress mechanism and poor health $[3,4]$. Most students at the university are limited to physical education in the framework provided by the Federal State Educational Standards. They basically have a common focus on physical development. More rarely, students choose extra-curricular forms of physical activity and attend sports sections.

Significant physical activity of students is necessary to compensate for the negative impact of active mental activity during university studies, fatigue and psycho-emotional stress during class. All this, in turn, contributes to the formation, preservation and strengthening of students' health.

In the Republic of Tuva, the socio-economic standard of living is significantly lower compared to other regions of Russia. High levels of poverty, unemployment, socially determined types of diseases, combined with uncomfortable climatic and geographical living conditions increase the risk of diseases and further reduce the body's adaptive resources [5].

The purpose of the study: to study and conduct a comparative analysis of the lifestyle characteristics of the Tuvan university physical education and non-physical education students.

\section{MATERIALS AND METHODS}

To study the lifestyle of Tuvan students, a questionnaire was used. It included students' self-assessment of living conditions, health status, physical development, nutrition, and sociodemographic characteristics of respondents. 151 physical education students (profiles "Physical education and sport"; "Physical education with safety of life") and 218 students of the non-physical culture faculty (history; jurisprudence, biology, mathematics) were interviewed.

\section{RESULTS AND DISCUSSION}

Self-assessment of one's physical condition allows to develop reflection skills. They are means of complete and effective introspection, allowing to evaluate own thoughts, actions, determine one's position in life, life priorities, analyze them and change them and directly affects lifestyle.

As a result of self-assessment of their level of physical development, students were divided as follows (Fig. 1).

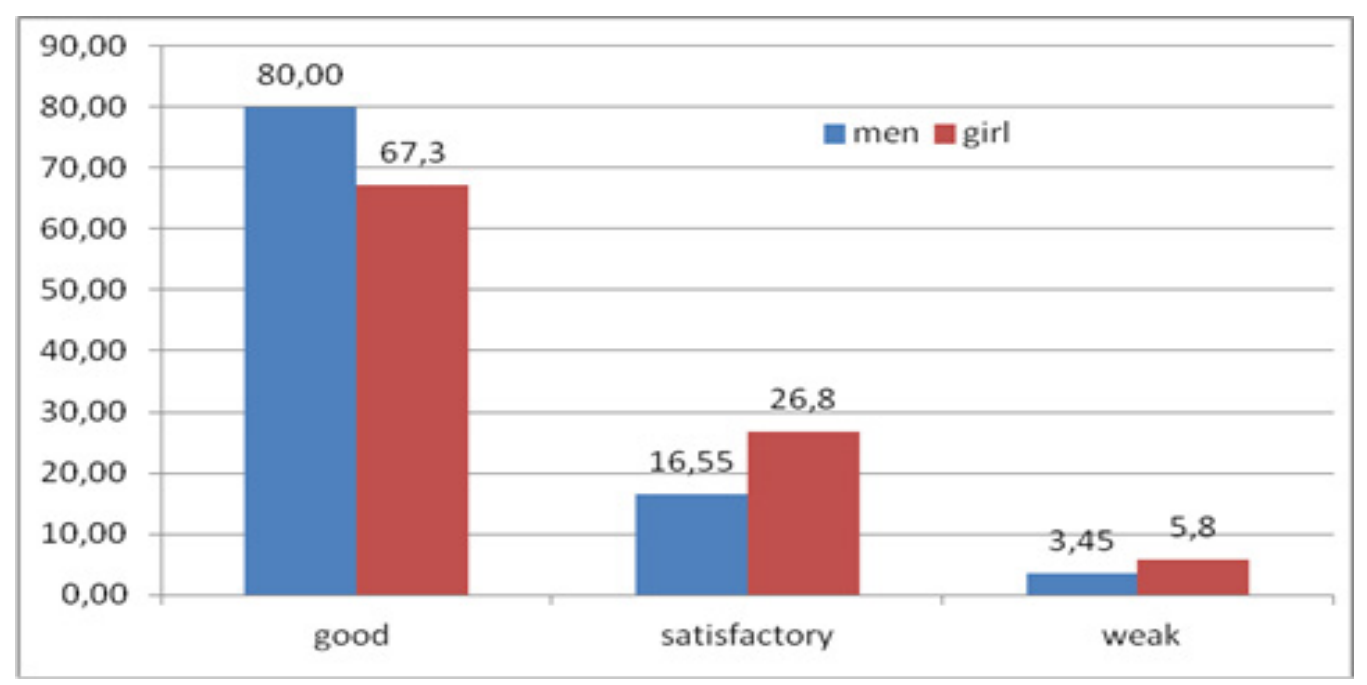

Fig. 1. Distribution of students by self-assessment of their physical development 
Most girls and boys rate their physical development as good, with $12.6 \%$ more among boys. Relatively more girls consider their physical development satisfactory and weak. We received the same data earlier; only the fact that the number of Tuvan students who rate their physical development as good was higher than ten years ago [6].

Self-esteem of their physical development significantly exceeds the objective results of a student survey. So, according to some studies, the average level of physical development prevails among students. A high level of physical development is manifested only in $3-4 \%$ of students $[7,8]$.

From the literature it is clear that the level of physical development in megacities is higher than in small cities. It is due to a complex of socio-economic conditions [9].

An analysis of the self-assessment of the students physical development in physical education and non-physical education is presented in Fig. 2.

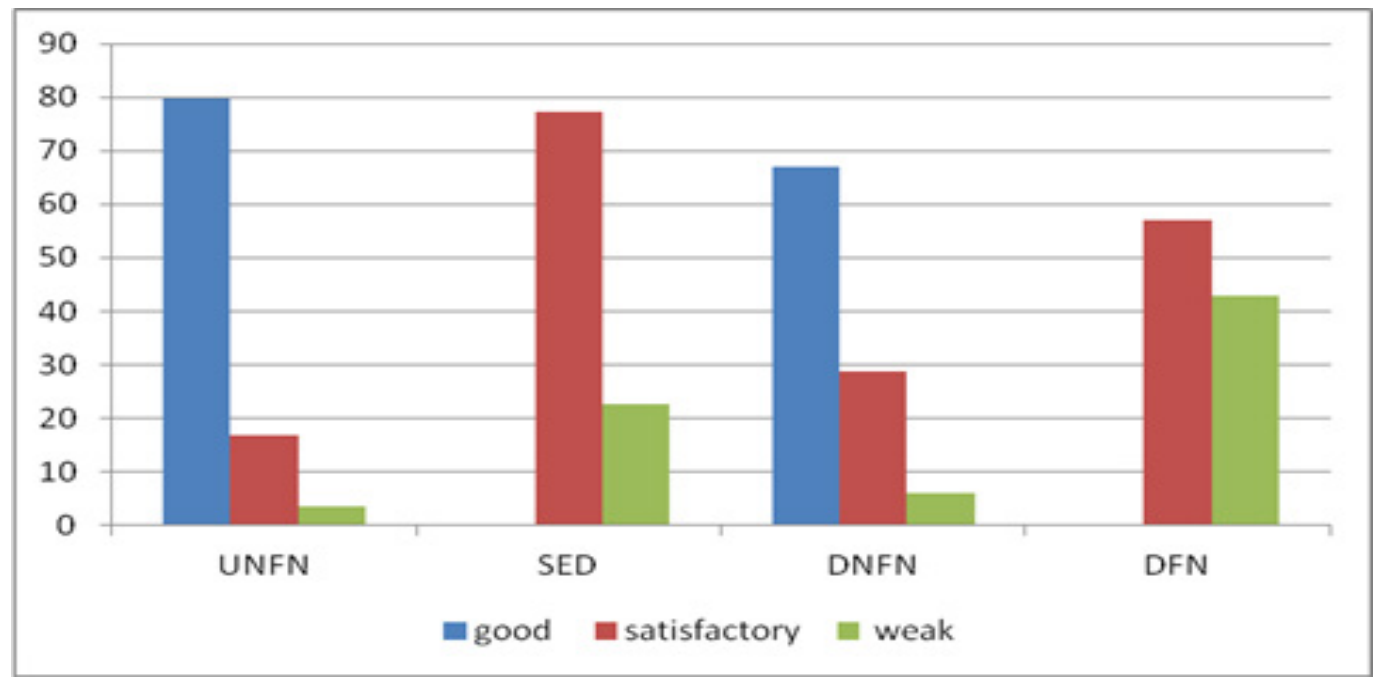

Please note, UNFN, DNFN are not sports boys and girls; SFD, DFN - sports men and women

Fig. 2. Self-assessment of the students physical development in physical education and non-physical education (\%)

A higher assessment of their physical good, and in DNF there are more than half (67.1\%). development in young men, both physical education When asked about self-esteem of their and non-physical education. In DNF, self-esteem is health, most students consider their health to much higher, since in DNF, as a rule, there are no be good, and only $53.2 \%$ of SFD consider it to be respondents who rate their physical development as excellent.

Table 1 - Student self-esteem

\begin{tabular}{|c|c|c|c|c|c|}
\hline \multirow{2}{*}{ Groups } & \multicolumn{5}{|c|}{ what I consider my health } \\
\cline { 2 - 6 } & Excellent & Good & Satisfactory & Weak & Can't rate \\
\hline UNFN & 41,4 & 46,5 & 8,1 & 2,0 & 2,0 \\
\hline SFD & 53,2 & 29,8 & 2,1 & 4,3 & 10,6 \\
\hline DNFD & 18,6 & 57,7 & 16,5 & 4,5 & 2,7 \\
\hline DFN & 0 & 71,4 & 14,3 & 14,3 & 0 \\
\hline
\end{tabular}

It is also important to note that DFN rated their health worse than anyone, because they have a relatively high proportion of respondents with satisfactory and poor health, in the absence of excellent health assessment (Table 1).
The health-saving task of the university should be solved not only with the help of an external system of control over the physical condition, but also due to the ability to independently evaluate the advantages and disadvantages of their physical 
condition. In general, everyone agrees that everyone is responsible for their health, but not everyone takes practical steps to maintain it, justifying it with the lack of free time, conditions, desire.

To the question "What interferes with health?" The boys and girls of a non-sports field answered - a lot of work. Among the respondents of the physical education trend, young men noted fatigue, and girls - fatigue and lack of time. It is likely that students in the sports field are experiencing excessive physical exertion. While students in the non-sports field allow themselves to justify their inability to influence their own health due to lack of time.

It should be noted that a special form of improving physical development and strengthening health is a systematic training in health gymnastics. It has a general strengthening anti-stress character, stimulates the production of endorphins and improves the emotional state of the body.

Only about $15 \%$ of students regularly do morning exercises, and these are mainly students Table 2 - Student self-esteem (\%) from the non-sports group, SFN do not do this because there are no conditions, and DPF, although they do morning exercises, is irregular. It is likely that students with a physical orientation believe that they are already quite busy in certain sports and do not need morning exercises.

The duration of the disease for about two months was noted by respondents from the physical education group: $13.5 \%$ of boys and $14.3 \%$ of girls. Students who were not involved in sports were less sick: from 41.4 young men to $38.4 \%$ of girls were not sick at all during the year, or $48.5 \%$ and 50.5\% were sick for less than a week, respectively. The long duration of illness among students in the field of sports is additionally associated with sports injuries.

An important component of a person's healthy lifestyle, indicators of his financial situation and standard of living are the quantitative and qualitative characteristics of his nutrition. It has been established that the health status of students depends on the quality of nutrition [10-13].

\begin{tabular}{|c|c|c|c|c|c|c|}
\hline \multirow{2}{*}{ groups } & \multicolumn{3}{|c|}{ Do you have breakfast? } & \multicolumn{3}{c|}{ How do you eat: } \\
\cline { 2 - 7 } & Yes & No & Sometimes & I eat well & $\begin{array}{c}\text { Not eating } \\
\text { enough }\end{array}$ & $\begin{array}{c}\text { Constantly } \\
\text { lacking food }\end{array}$ \\
\hline UNFN & 67,0 & 12,0 & 21,0 & 78,0 & 18,0 & 4,0 \\
\hline SFD & 36,5 & 36,5 & 26,9 & 48,8 & 39,5 & 11,6 \\
\hline DNFD & 60,4 & 13,5 & 26,1 & 72,8 & 23,6 & 3,6 \\
\hline DFS & 42,9 & 28,6 & 28,6 & 50,0 & 50,0 & 0,0 \\
\hline
\end{tabular}

Significantly more respondents of nonphysical education have breakfast, unlike students of physical education, they are about half as much (Table 2). Exactly the same addiction for those who do not eat breakfast at all. Between 20 and 30\% of all respondents eat breakfast from time to time.

The same dependence is observed in relation to nutrition: respondents who are not involved in sports eat more fully, eat completely. Among those who do not eat enough, DFN prevails (50.0\%). More youth are constantly malnourished among athletes (11.6\%). For boys and girls, physical education is about $4 \%$.

Thus, physical education students have worse nutritional characteristics.

Good nutrition is provided by a good financial position.

Answering a question about livelihoods, respondents in the profile of physical education called work - $46.7 \%$ of boys and $57.1 \%$ of girls combine work with study, which probably explains the fact that these students are very tired. Boys in this group also indicated a scholarship as a source of livelihood - 53.3\%, but girls were only $28.6 \%$. 
Respondents who are not involved in sports provide for their financial situation mainly at the expense of parents and other relatives.

Young men, regardless of direction, believe that they are wealthy, fewer girls, and both groups indicate approximately the same number

Table 3 - Self-assessment of students bad habits (\%) of respondents whose financial situation does not allow for good nutrition.

We analyzed the answers associated with bad habits. The most common habits in an unhealthy lifestyle are traditionally smoking and drinking alcohol (Table 3).

\begin{tabular}{|c|c|c|c|c|c|c|}
\hline \multirow{2}{*}{ groups } & \multicolumn{3}{|c|}{ Do you smoke? } & \multicolumn{3}{c|}{ Do you drink alcohol? } \\
\cline { 2 - 7 } & No & irregularly & constantly & no & $\begin{array}{c}\text { only on } \\
\text { holidays }\end{array}$ & More often \\
\hline UNFN & 79,8 & 13,1 & 7,1 & 68,7 & 29,3 & 2,0 \\
\hline SFD & 93,3 & 6,7 & 0,0 & 32,6 & 67,4 & 0,0 \\
\hline DNFD & 70,4 & 28,3 & 1,3 & 78,1 & 20,7 & 1,2 \\
\hline DFS & 94,3 & 4,8 & 0,9 & 33,3 & 66,7 & 0,0 \\
\hline
\end{tabular}

Most of the respondents do not smoke, but non-sports students have more people with accidental smoking. It is especially true for DNPF. 7.1\% of smokers UNFN.

Of concern is the relatively high proportion of respondents who drink alcohol on holidays, especially in the non-sports group, among students engaged in physical education, but about three times less.

\section{CONCLUSION}

The result of the university students physical development self-assessments analysis by physical and non-physical profiles showed the presence of ambivalence with a fairly high selfesteem of the inadequate actual state of affairs in the physical development and health of a modern person. students. It turned out that the lack of personal interest in improving physical condition and maintaining health is especially characteristic of students who do not play sports. Non-athletic boys and girls justify their lack of interest in improving their health with the traditional response to high employment. Among respondents, trends in physical education students indicate fatigue due to excessive physical activity.

A relatively small proportion uses general strengthening types of physical activity as morning exercises. A very large proportion of people with physical education who constantly smoke and drink alcohol on holidays, and not just on holidays, are of serious concern.

Awareness of personal responsibility for the formation, preservation and strengthening of health and the ability to objectively assess one's physical condition is an important general cultural competence of any university student.

\section{REFERENCES}

1. Mikhailova T.V. On the essence of design activities of students of the primary vocational education system. Nauchnyj poisk. 2013; 4: 53-54 [In Russ.].

2. Epifanov K.N., Mikhailova T.V.Efficiency of formation of the trust units to professional coaching for the students of institutes of sport. Fizicheskaya kul'tura: vospitanie, obrazovanie, trenirovka. 2016; 6: 59.

3. Kruglyakova I.P. Priority factors affecting the health of students. Vestnik YuUrGU. Seriya "Obrazovanie, zdravoohranenie, fizicheskaya kul'tura". 2003; 2.5(21): 140-141 [In Russ.].

4. Vilenskiy M.Ya. Procedural characteristics of the emergence and development of value relations of students to physical culture in higher education. Pedagogicheskoe obrazovanie I nauka. 2013; 4: 6-14 [In Russ.].

5. Khasnulin V.I., Khasnulina A.V. the Significance of psychosocial factors in the formation of adaptive human stability to the ecologically conditioned Northern stress. Mir nauki, kul'tury, obrazovaniya. 2001; 5: 235-240 [In Russ.].

6. Buduk-ool L.K., Aizman R.I. Physical development and health of students in uncomfortable climatic and geographical conditions of residence. Kazanskij medicinskij zhurnal. 2009; 
4: 567-569 [In Russ.].

7. Legotkin A.N., Abyzova T.V., Legotkina L.R. Assessment of the level of health and physical fitness of students. Pedagogiko-psihologicheskie I medico-biologicheskie problemy fizicheskoj kul'tury I sporta = Pedagogico-psychological and medicobiological problems of physical culture and sport. 2013; 8(1): 126-132. URL: http://journalsport.ru/ images/vipuski/8-1/1.pdf [In Russ., In Engl.].

8. Gaptar M.I., Kovaleva O.A. Assessment of the functional state and physical development of students. Sovremennye problemy formirovaniya zdorovogo obraza zhizni u studencheskoj molodezhi: Materialy Mezhdunarodnoj nauchnoprakticheskoj internet konferencii [Modern problems of forming a healthy lifestyle among students: Materials International scientifical practical internet conference]. 2018: 3-7 [In Russ.].

9. Sineva I.M., Negasheva M.A., Popov Yu.M. Comparative analysis of the level of physical development of students in different cities of Russia. Anthropology. Vestnik Moskovskogo universiteta. Seriya XXII. 2017; 4: 17-27 [In Russ.].

10. Buduk-ool L. K. Socio-hygienic factors of students' lifestyle. Gigena I sanitariya. 2015; 94.5: 95-97 [In Russ.].

11. Baguet G., Van Praagh E., Berthoin S. Endurance training and aerobic fitness in young people. Sports Medicine. 2003; 15: 1127-1143.

12. Brunet J., Sabiston C.M. Social physique anxiety and physical activity: A selfdetermination theory perspective. Psychology of Sport Exercise. 2009; 10: 329-335.

13. Phillips E., Davids K., Renshaw I., Portus M. Expert performance in sport and the dynamics of talent development. Sports Medicine. 2010; 40: 271-283.

14. Suslov F. About the sensitive age periods in the development of physical capabilities. Modern Athlete and Coach. 2002; 40: 31-33.

\section{Submitted: 27.02.2020}

Larisa K. Buduk-ool - Doctor of Biological Sciences, Professor, Tuva State University, 6670oo Russia, Kyzyl, Lenina str., House 58, block 91,e-mail: buduk-ool@mail.ru

Ayana M. Khovalyg - Lecturer, Tuva State University, 667002, Russia, Kyzyl, Tsentralnaya str., House 7oA, e-mail: choixam@mail.ru 